\title{
Very Low Birth Weight Preterm Children Motor Performance in the First Year of Life
}

\section{Desempenho Motor de Prematuros de Muito Baixo Peso ao Nascer no Primeiro Ano de Vida}

\author{
Lenise Baldin Cavazzola*a; Natiele de Mello de Oliveira ${ }^{\mathrm{a}}$; Mayra Nathu Lodia ${ }^{\mathrm{a}}$ Bruna Chiarani ${ }^{\mathrm{a}}$; Fernanda Trubian ${ }^{\mathrm{a}}$;
} Caroline Cenci Sangalia; Laura de Moura Rodrigues ${ }^{a}$; Raquel Saccani ${ }^{a}$

\author{
${ }^{a}$ Universidade de Caxias do Sul, Physiotherapy Course. RS, Brasil. \\ *E-mail: lenise.cavazzola@gmail.com \\ Recebido em: 29/05/2020 \\ Aprovado em: 03/09/2020
}

\begin{abstract}
Motor skills acquisition is negatively affected by low birth weight in preterm infants. This research aimed to evaluate the motor development of preterm babies from zero to 12 months of corrected age, born with very low birth weight. The sample of 45 children, from 2 to 12 months of chronological age, was divided into two groups: Group A (from 0 to 6 months, $n=35$ ) and Group B (from 7 to 12 months, $n=10$ ). In order to assess the motor skill development, Alberta Infant Motor Scale (AIMS) was used along with two questionnaires to control the biological and environmental risk factors. In the results $53,3 \%$ of the children were preterm below 30 weeks gestational age, and more than $40 \%$ of the evaluated population presented a poor motor performance for the age, with $13.3 \%$ of the referred children as having abnormal motor development and 35.6\%, suspicious of delayed motor development. The worst performance could be observed in Group B. The findings reinforce the importance of early assessment, considering that the first semester is the most critical period for the child's neuropsychomotor development.
\end{abstract}

Keywords: Infant, Premature. Motor Skills. Infant, Very Low Birth Weight.

\section{Resumo}

O baixo peso ao nascer afeta negativamente as aquisições motoras dos prematuros. Esta pesquisa teve como objetivo avaliar o desenvolvimento motor de bebês pré-termos de zero a 12 meses de idade corrigida, nascidos de muito baixo peso. Participaram da pesquisa 45 crianças, com idade entre 2 e 12 meses de idade cronológica, divididas em 2 grupos: Grupo A (0 a 6 meses, $n=35)$ e grupo B (7 a 12 meses, $n=10)$. Para avaliação motora foi utilizada a Alberta Infant Motor Scale (AIMS) e dois questionários para controle dos fatores de risco biológicos e ambientais. Nos resultados, 53,3\% das crianças eram prematuras com idade gestacional menor que 30 semanas e mais de $40 \%$ da população avaliada apresentou desempenho motor inadequado, sendo que 13,3\% apresentaram atraso e 35,6\% suspeita de atraso. O pior desempenho foi observado no grupo A. Os achados reforçam a importância da avaliação precoce, considerando que o primeiro semestre é o período mais crítico ao desenvolvimento motor.

Palavras-chave: Recém-Nascido Prematuro. Destreza Motora. Recém-Nascido de muito Baixo Peso.

\section{Introduction}

The World Health Organization - WHO ${ }^{1}$ defines newborn infants with gestational age of less than 37 weeks as premature. Every year, it is estimated that there are 15 million births of premature babies, and Brazil is the $10^{\text {th }}$ place among the countries with the highest number of preterm births. In addition to the low gestational age representing an important risk for the newborn's survival, when associated with low birth weight, may cause even greater risks than when one of these conditions presents itself alone ${ }^{2}$ WHO estimates that 15 to $20 \%$ of the world's births have low birth weight. Very low birth weight categorization is given to infants weighing between 1.000 and 1.499 grams $^{1}$ and the lower the birth weight, the higher the sequels and the repercussions on motor development ${ }^{3}$.

The risk of compromising the infants' motor development is proportionally higher the lower the gestational age and birth weight. These factors tend to have a negative effect on motor acquisitions since the first months, and may extend to more advanced ages in children ${ }^{3}$. Very low birth weight associated with other biological and environmental risk factors may affect the motor skills survival of premature babies ${ }^{4}$, which often present a greater delay in growth and development compared to full-term babies, especially in the first year of life, considering the expected abilities for corrected age ${ }^{5}$.

Several risk factors for the development of premature infants with very low birth weight should be taken into account, such as the presence of comorbidities, the need to stay in a neonatal intensive care unit for long periods, clinical intercurrences, functional and physiological immaturity of the brain and organs, in addition to environmental factors such as the family socioeconomic conditions ${ }^{3,6}$. In view of this variety of risk factors, it is necessary to use accurate assessments to determine changes that may appear in the long term in the neuropsychomotor development of these babies. Early evaluation will make it possible to develop effective inter- 
ventral programs that will assist in the motor skills acquisition of these children ${ }^{6}$.

Therefore, although the development of very low birth weight premature babies may present problems in several domains, extending throughout childhood, intervention programs focused on development may favor the children's motor performance and long-term cognitive abilities ${ }^{7}$. Early intervention and multidisciplinary follow-up favor the motor development and attenuation of morbid aspects associated with prematurity and very low, especially in children from low-income families, whose environmental risk factors may be an aggravating factor to the already existing biological ones $^{7}$.

In this context, early evaluation and changes detection in motor development are essential in health services so that risk factors can be identified to which the child is exposed, minimizing their effects on motor acquisitions. Therefore, the objective of this study was to evaluate the motor development of babies born at very low birth weight, registered at the Highrisk Outpatient Clinic of the Clinical Center of Universidade de Caxias do Sul, from zero to 12 months of corrected age.

\section{Material and Methods}

\subsection{Design}

Descriptive and observational research, of comparative and associative nature, with a cross-sectional approach, approved by the Research Ethics Committee of Universidade de Caxias do Sul (UCS) (number 2.688.022).

\subsection{Sample}

A total of 45 preterm babies aged from zero to 12 months were included in the sample, considering the correction of gestational age. The sample was distributed in two groups: Group A: Composed of 35 babies from 0 to 6 months of age; Group B: Composed of 10 babies aged between 7 and 12 months. All participants are registered at the High-risk Outpatient Clinic of the Clinical Center (CENCLIN) of UCS, since they come from Hospital Geral of Caxias do Sul, after a period of hospitalization at the Neonatal Intensive Care Unit (NICU).

The study participants were included with parental consent, following the criteria: a) to be referred from the Neonatal ICU of Hospital Geral of Caxias do Sul; b) pre-term babies (born before 37 weeks of gestation); c) to be within the age range from 0 to 12 months of corrected age; d) to be in follow-up by physiotherapy professionals at the High risk Outpatient Clinic; e) to be born with very low weight (below 1,500g). On the other hand, the following participants were excluded: a) presented an inability to carry out evaluation ; b) diagnosis of confirmed neurological diseases; c) alteration of vital signs; d) deep sleep; e) intense crying f) no parents or guardians' consent. Thus, 11 participants ( 3 bearing myelomeningoceles; 1, plexus lesion; 6, cerebral palsy; 1, global developmental disorder) were excluded.

\subsection{Instruments}

Alberta Infant Motor scale, which was developed by Piper and Darrah ${ }^{9}$ in Canada, was used to evaluate the children's motor development, with infants from birth to 18 months of age. It has 58 items, subdivided in prone (21 items), supine (9 items), sitting (12 items) and standing (16 items) positions, which represent the sequence of motor acquisitions development. For each item, different aspects of the child's motor behavior are observed, such as the posture that the child assumes, her or his movement against severity and where weight support occurs; being allowed little handling of the evaluator ${ }^{9}$ and disregarding reflexes and reactions.

AIMS evaluates motor gains over time dynamically in infants, because it visualizes the evolution of these babies regardless of their diagnosis, enabling the investigation of the components for the acquisition of certain abilities, where the only intervention of the examiner is to hold the child in the sitting and standing posture and stimulate spontaneous movement and postural change with toys ${ }^{9,10}$. It is a research support tool that has been validated and standardized in different countries, including Brazil ${ }^{10}$. Validation reaffirms its potential for clinical and scientific diagnosis, confirming its power to evaluate postural acquisitions and screening for motor delays in children on terms and pre-terms over time ${ }^{10}$.

Two simple questionnaires were also used to control variables related to biological and environmental risk factors, such as: sex, chronological age and corrected age, gestational age, birth weight, birth length, head circumference, length of hospital stay (days), use of mechanical ventilation (days), father's age, mother's age and number of children.

\subsection{Procedures}

The children, accompanied by parents or guardians, were initially received by the multiprofessional team, passing through the physiotherapy team (composed of 3 college students per shift, and 2 physiotherapists), in an appropriate room at CECLIN High Risk Outpatient Clinic. First, the evaluation process was explained to parents and, by signing the informed consent form, the research questionnaires were applied, as well as the analysis of the outpatient control record and the national vaccination card. After that, the procedures for evaluation with AIMS were initiated, with an average duration of 20 minutes. During motor evaluation, the child was observed in the different positions, having as little clothing as possible and through minimal management by the therapists. Only sensory-motor stimuli were performed with the use of sound-emitting and colored toys. It is also noteworthy that for the evaluations, the researchers were previously trained with the instrument, until reaching the inter-evaluators agreement indicated by the scale.

For each item observed, a point was assigned and 0 for 
each posture not acquired by the child yet. After the sum of the items evaluated ( 0 to 58 points) per posture, the gross score was converted from zero to $100 \%$ percentile. Motor development was considered abnormal when below 5\%; suspicious, between $6 \%$ and $24 \%$; and considered normal, above $25 \%$ in the percentile scale ${ }^{10}$.

The data collected were analyzed using the SPSS statistical program (version 20.0). Descriptive statistics with simple and relative frequency distribution, as well as central tendency (mean/median) and variability (standard deviation) measures were used. Pearson's Chi-square test was used for associations of the children's motor development categorization between the groups, with a significance level of $5 \%$. For comparisons among groups of quantitative variables, the independent $t$ test was adopted, considering a significance level of $5 \%$.

\section{Results and Discussion}

Regarding the general biological characteristics of the 45 babies ( 22 boys and 23 girls), it was observed that age ranged from 2 to 12 months of chronological age and 0 to 10 months of corrected age. The children presented several biological risk factors, highlighting that $53.3 \%(n=24)$ were premature infants with gestational age lower than 30 weeks. Regarding the type of delivery, $20.0 \%(n=9)$ of the children were born from normal delivery and $80.0 \%(n=36)$ from cesarean delivery. The description of biological and environmental characteristics is available in Table 1, in which homogeneity is observed between the groups $(p>0,05)$ for all the variables analyzed.

Table 1 - Biological and environmental characteristics (mean \pm standard deviation) of babies in groups $A(0$ to 6 months, $\mathrm{n}=35)$ and $\mathrm{B}$ (7 to 12 months, $\mathrm{n}=10$ )

\begin{tabular}{|c|c|c|c|c|}
\hline Biological characteristics & Total $(n=45)$ & Group A & Group B & \multirow{2}{*}{$\begin{array}{c}P \\
(\text { test } t)\end{array}$} \\
\hline & \multicolumn{3}{|c|}{ Mean \pm SD } & \\
\hline Gestational age (weeks) & $30.11 \pm 2.21$ & $30.14 \pm 2.07$ & $30.0 \pm 2.78$ & 0.88 \\
\hline Corrected age (months) & $3.42 \pm 3.07$ & $2.11 \pm 2.01$ & $8.0 \pm 0.94$ & - \\
\hline Chronological age (months) & $5.59 \pm 3.19$ & $4.37 \pm 2.21$ & $10.30 \pm 0.94$ & - \\
\hline Birth weight $(\mathrm{kg})$ & $1.18 \pm 0.19$ & $1.20 \pm 0.17$ & $1.11 \pm 0.24$ & 0.31 \\
\hline Birth Length $(\mathrm{cm})$ & $37.58 \pm 3.22$ & $37.78 \pm 3.32$ & $36.90 \pm 2.93$ & 0.42 \\
\hline Head circumference $(\mathrm{cm})$ & $27.19 \pm 1.91$ & $27.29 \pm 1.71$ & $26.85 \pm 2.55$ & 0.61 \\
\hline Number of prenatal consultations & $5.72 \pm 1.94$ & $5.74 \pm 1.67$ & $5.67 \pm 2.87$ & 0.94 \\
\hline Hospital stay time (days) & $52.51 \pm 26.10$ & $53.60 \pm 25.94$ & $48.70 \pm 27.70$ & 0.62 \\
\hline Use of mechanical ventilation (days) & $7.89 \pm 13.96$ & $8.80 \pm 15.47$ & $4.70 \pm 5.87$ & 0.20 \\
\hline Father's age & $31.38 \pm 8.76$ & $30.60 \pm 8.34$ & $34.10 \pm 9.79$ & 0.32 \\
\hline Mother's age & $26.78 \pm 7.56$ & $27.29 \pm 8.01$ & $25 \pm 5.73$ & 0.32 \\
\hline Number of children & $1.65 \pm 0.73$ & $1.67 \pm 0.73$ & $1.57 \pm 0.78$ & 0.77 \\
\hline Apgar 5th minute - Median (25-75) & $8.5(8-9)$ & $8(8-9)$ & $9(6.75-9)$ & 0.83 \\
\hline Environmental characteristics & \multicolumn{3}{|c|}{ FR (n) } & $P\left(\mathrm{Chi}^{2}\right)$ \\
\hline Income in wages & & & & 0.72 \\
\hline 1 to 2 & $62.2(28)$ & $59.9(21)$ & $70(7)$ & \\
\hline 3 to 4 & $33.4(15)$ & $34.3(12)$ & $30(3)$ & \\
\hline 5 to 7 & $4.4(2)$ & $5.8(2)$ & - & \\
\hline Father's schooling & & & & 0.31 \\
\hline Never studied & $2.2(1)$ & - & $10(1)$ & \\
\hline 1st degree incomplete & $28.9(13)$ & $28.6(10)$ & $30(3)$ & \\
\hline 1st degree complete & $17.8(8)$ & $17.1(6)$ & $20(2)$ & \\
\hline Incomplete high school & $20(9)$ & $22.9(8)$ & $10(1)$ & \\
\hline Complete high school & $22.2(10)$ & $20(7)$ & $30(3)$ & \\
\hline Higher education & $8.8(4)$ & $11.4(4)$ & - & \\
\hline Mother's schooling & & & & 0.22 \\
\hline Never studied & - & - & - & \\
\hline 1st degree incomplete & $15.6(7)$ & $14.3(5)$ & $20(2)$ & \\
\hline 1st degree complete & $22.2(10)$ & $20(7)$ & $30(3)$ & \\
\hline Incomplete high school & $24.4(11)$ & $22.9(8)$ & $30(3)$ & \\
\hline Complete high school & $31.1(14)$ & $34.3(12)$ & $20(2)$ & \\
\hline Higher education & $6.7(3)$ & $8.6(3)$ & - & \\
\hline
\end{tabular}

Legend: $\mathrm{N}=$ number; $\mathrm{FR}=$ frequency; $\mathrm{cm}=$ centimeters.

$\mathrm{p}$ of comparison (independent $\mathrm{t}$ test) and association $\left(\mathrm{Chi}^{2}\right)$ between the groups.

Source: Research data. 
Regarding the participants' motor performance, it was found that $13.3 \%$ showed delayed motor development, $35.6 \%$ were classified as suspicious motor development and 51.1\% presented adequate motor development for the corrected age. Considering the groups, infants in group A presented worse motor performance, compared to babies in group B, as shown in Figure 1.

Figure 1 - Distribution (\%) of classification obtained in AIMS by the babies in groups A ( 0 to 6 months, $n=35)$ and $B$ ( 7 to 12 months, $\mathrm{n}=10$ )

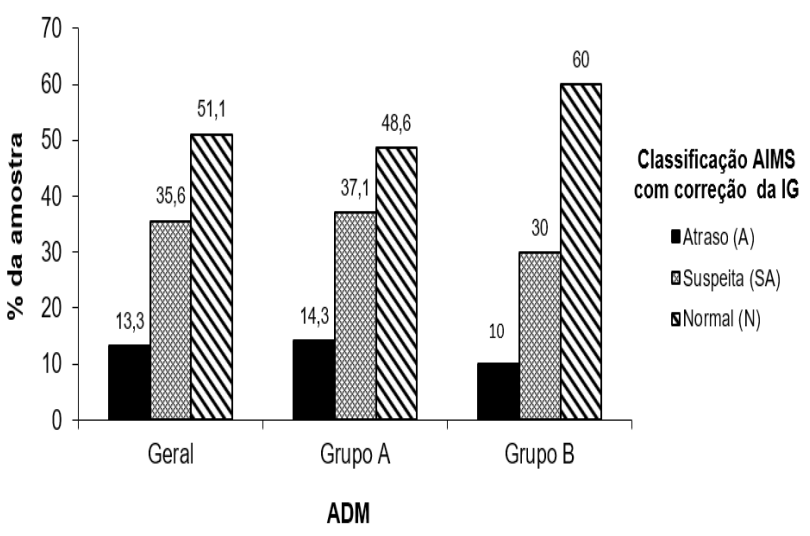

Source: Research data.

More detailed analysis of percentile values and classification criteria (delay, suspicion of delay and normality in performance) are shown in Table 2. The percentiles analysis indicates that the values were low, especially considering the general sample and group A. In the comparison between the groups, children over 7 months showed better motor performance considering the percentile, but without significant difference $(p=0.12)$. The same is observed when analyzing the classification criterion, where group A shows a higher number of children with performance below expected (A and SA), although without significant difference $(\mathrm{p}=0.54)$.

Table 2 - AIMS scores (mean \pm standard deviation), percentile and classification of the babies' motor performance in groups $\mathrm{A}$ $(\mathrm{n}=35)$ and $\mathrm{B}(\mathrm{n}=10)$

\begin{tabular}{|c|c|c|c|c|}
\hline $\begin{array}{c}\text { Motor } \\
\text { Performance } \\
\end{array}$ & Total & Group A & Group B & $P($ test $t)$ \\
\hline \multicolumn{5}{|c|}{ Mean \pm SD } \\
\hline Percentile & $29.60 \pm 22.86$ & $26.2 \pm 20.59$ & $41.50 \pm 27.39$ & 0.12 \\
\hline \multicolumn{4}{|c|}{ FR (n) } & $P\left(\mathrm{Chi}^{2}\right)$ \\
\hline \begin{tabular}{|l|} 
Categorization \\
\end{tabular} & & & & 0.54 \\
\hline Delayed(A) & $13.3(6)$ & $14.3(5)$ & $10(1)$ & \\
\hline \begin{tabular}{|l|} 
Suspicious(SA) \\
\end{tabular} & $35.6(16)$ & $37.1(13)$ & $30(3)$ & \\
\hline Normal(N) & $51.1(23)$ & $48.6(17)$ & $60(6)$ & \\
\hline \multicolumn{5}{|c|}{$\begin{array}{l}\text { Legend: AIMS }=\text { Alberta children's motor scale; } p \text { of comparison between } \\
\text { groups; percentile and classification of participants' motor performance } \\
\text { according to AIMS. }\end{array}$} \\
\hline
\end{tabular}

The present study analyzed the motor development of preterm and very low weight babies through the Alberta Infant Motor scale. The results obtained showed that more than $40 \%$ of the population evaluated presented inadequate motor performance for age, and the worst motor performance could be observed in babies up to 6 months old. The difference found between the two groups may have been influenced by the different risk factors to which premature newborns are exposed.

Prematurity is a risk factor for child development, and may cause future school difficulties, behavioral problems and worse motor repertoire. In addition to early birth, exposure to other biological and environmental conditions can be decisive in the performance of these babies ${ }^{11}$. Previous study states that a greater biological threat to typical development is associated with birth lower than 32 weeks' gestational age and weighing less than 1.500 grams $(\mathrm{g})^{4}$. As a biological impact, the literature highlights the greatest vulnerability to neurological complications, developmental deficits and growth of premature newborns. Therefore, children born less than 32 weeks of gestation usually present higher motor and neurological impairment, which may persist until adolescence and adulthood, and therefore it is necessary to follow up the development of this population, since this is an individual process $^{12}$. In this study, in addition to the very low weight, it was observed that $53.3 \%$ of the babies were born with gestational age lower than 30 weeks.

Literature points out that babies born with very low weight and extreme low weight are at a disadvantage, and that they present a great possibility of growth retardation, motor performance delay and death ${ }^{13}$. Similarly, Nuysink et al. ${ }^{14}$, state that the lower the gestational age or birth weight, the greater the probability for the delay or impairment of the development of these babies. Furthermore, these authors reported that extreme prematurity may reflect on gait acquisition, since $50 \%$ of the sample was able to perform gait independently only three months after full-term babies acquired this motor stage, although age was corrected. They also point out that the ability to perform gait independently at 15 months was associated with the results obtained through AIMS at 6 months. The same is observed in the present study, since part of the sample presented delays in motor acquisitions even with the gestational age correction.

The sample of the present study is considered high risk, since it is exposed to both biological and environmental factors and has motor characteristics below the expected level. In line with the results of this research, the study carried out by Fuentefria et al. ${ }^{4}$ highlights a greater vulnerability of premature infants exposed to risk factors when compared to full term infants. In the research, they found that preterm infants at 8 and 18 months of life had a significantly lower motor performance than those at term. The anthropometric measurements of the groups were also monitored, in which it was found that in the group of premature infants the growth pattern was considered lower, especially for those born with a weight of less than $1.500 \mathrm{~g}$. Thus, the authors state that nutritional status is an important factor that influences the 
motor performance of preterm babies. Therefore, the growth impact on infant motor development is evident, a fact that justifies the findings, in which approximately $48 \%$ of the sample studied (composed of infants with less than $1.500 \mathrm{~g}$ ) presented inadequate performance for the corrected age.

The results found in AIMS indicated that, although the percentiles above 25 already indicate normality, the mean sample was below 50. According to Eickmann et al. ${ }^{15}$, the biological vulnerability caused by prematurity and low weight is identified as one of the main risk factors for developmental delays due to the immaturity of systems and organs, which may lead to difficulties in adapting to different environmental stimuli, which also generates impact on motor acquisitions.

When the performance between the groups was compared, although without significant difference, the babies from 0 to 6 months presented a worse percentile and categorization. This finding leads to the belief that in the first half of life the child is more vulnerable to the influence of biological variables, such as extreme prematurity and low weight. Corroborating these results, other studies carried out with premature infants and low-weight infants reported that preterm infants up to 6 months of corrected age showed greater delay than older babies. They also point out that motor behavior is the most affected domain in the development of infants born prematurely, since they usually present immature motor and brain systems, which may interfere in the ability to develop good postural control ${ }^{6,8,16}$.

In the same aspect, in line with the present research, a previous study carried out with preterm babies observed that the highest number of motor abilities appeared after the $6^{\text {th }}$ month of life $(6-8$ months $)$, suggesting that motor development in premature infants occurs differently in relation to full term births. This is because the biological and environmental factors to which these babies are exposed should be considered, especially in developing countries such as Brazil ${ }^{6,17}$. In addition, parents' overprotection, especially in pre-test babies, may disfavor contact with the stimuli necessary for the motor landmarks acquisition, due to the restriction related to task and context, and may potentiate the behavioral disorders ${ }^{18}$. Formiga et al. ${ }^{17}$ observed an improvement in the children's motor abilities after the first semester of life, assigning this to factors related to the child's organism in response to the environment demands, to the stimuli offered and to the changes in posture. Thus, the hypothesis is reinforced that in the second half of life environmental factors have a greater impact on child development. This is because, probably, after the first months of life, parents lose fear and Farmiga feel encouraged, start to stimulate the child more, maximizing the motor acquisitions process.

It should also be pointed out that, in the first months of life, premature babies usually remain in hospital, which potentiates existing biological risk factors and limits adequate environmental stimulation. The literature points out that factors such as time on mechanical ventilation, hospitalization and exposure to the hospital environment have an association with developmental delays, directly influencing the motor development of children up to 6 months of life ${ }^{19}$. Giachetta et al. ${ }^{20}$ justifies this fact by the deprivation of stimuli, both sensory and motor, characteristic of the hospital environment.

In view of the above, it is important to emphasize the importance of intervention measures to minimize future sequels and to promote a better quality of life for children, thus avoiding that alterations remain at an older age $\mathrm{a}^{7,11}$. Within this context, it is also noteworthy how significant the intervention and guidance performed with parents is, since adequate maternal practices proved effective in improving the child's motor repertoire ${ }^{21-23}$.

\section{Conclusion}

From the results of this research, changes in the motor development of premature children born with very low weight are evident, especially in the first 6 months of life. The findings reinforce the importance of early premature babies' evaluation, considering that the first semester is the most critical period for the child neuropsychomotor development. Based on the results obtained, it is noted that health professionals need to be alert to this portion of the child population, and public managers need to invest in programs that accompany the development of this risk population.

This study presented some limitations, such as the small sample number and the difference between the groups, with greater representativeness in group A. in addition, a longitudinal follow-up would allow to infer more safely the results found in the sample. However, the results of this research should be considered, since they indicated that premature infants with very low birth weight presented greater delays in the first half of life; period of alert to health teams that accompany these children.

\section{References}

1. World Health Organization. International statistical classification of diseases and related health problems. Genebra: WHO; 2016.

2. Blencowe H, Cousens S, Oestergaard MZ, Chou D, Moller $\mathrm{AB}$, Narwal R, et al. National, regional, and worldwide estimates of preterm birth rates in the year 2010 with time trends since 1990 for selected countries: a systematic analysis and implications. Lancet 2012;379(9832): 2162-72. doi: $10.1016 / \mathrm{S} 0140-6736(12) 60820-4$

3. Sampaio TF, Nogueira KPA, Pontes TB, Toledo AM. Comportamento motor de lactentes prematuros de baixo peso e muito baixo peso ao nascer. Fisioter Pesq 2015;22(3):25360. doi: 10.590/1809-2950/13533022032015

4. Fuentefria RN, Silveira RC, Procianoy RS. Neurodevelopment and Growth of a Cohort of Very Low Birth Weight Preterm Infants Compared to Full-Term Infants in Brazil. Am J Perinatol 2018;35(2):152-62. doi: 10.1055/s-0037-1606351

5. Pin TW, Darrer T, Eldridge B, Galea MP. Motor development from 4 to 8 months corrected age in infants born at or less than 
29 weeks' gestation. Dev Med Child Neurol 2009;51(9):73945. doi: 10.1111/j.1469-8749.2009.03265.x

6. Cabral TI, Silva LGP, Tudella E, Martinez CMS. Motor development and sensory processing: a comparative study between preterm and term infants. Res Dev Disabil 2015; 36(Supl I):102-7. doi: 10.1016/j.ridd.2014.09.018

7. Silveira RC, Mendes EW, Fuentefria RN, Valentini NC, Procianoy RS. Early intervention program for very low birth weight preterm infants and their parents: a study protocol. BMC Pediatr 2018;18(1):1-11. doi: 10.1186/s12887-0181240-6

8. Su YH, Jeng SF, Hsieh WS, Tu YK, Wu YT, Chen LC. Gross motor trajectories during the first year of life for preterm infants with very low birth weight. Phys Ther 2017;97(3):36573. doi: $10.1093 / \mathrm{ptj} / \mathrm{pzx} 007$

9. Piper MC, Pinnell LE, Darrah J, Maguire T, Byrne PJ. Construction and validation of the Alberta Infant Motor Scale (AIMS). Can J Public Health 1992;83(Suppl 2): S46-50.

10. Saccani R, Valentini NC, Pereira KR. New Brazilian developmental curves and reference values for the Alberta infant motor scale. Infant Behav Dev 2016;45(Pt A):38-46. doi: 10.1016/j.infbeh.2016.09.002

11. Moreira RS, Magalhães LC, Alves CRL. Effect of preterm birth on motor development, behavior, and school performance of school-age children: a systematic review. J Pediatr 2014;90(2):119-34. doi: 10.1016/j.jped.2013.05.010

12. Olsen JE, Allinson LG, Doyle LW, Brown NC, Lee KJ, Eeles AL, et al. Preterm and term-equivalent age general movements and 1-year neurodevelopmental outcomes for infants born before 30 weeks' gestation. Dev Med Child Neurol 2018;60(1):47-53. doi: 10.1111/dmcn.13558

13. Tchamo ME, Prista A, Leandro CG. Low birth weight, very low birth weight and extremely low birth weight in African children aged between 0 and 5 years old: a systematic review. J Dev Orig Health Dis 2016;7(4):408-15. doi: 10.1017/ S2040174416000131

14. Nuysink J, van Haastert IC, Eijsermans MJ, KoopmanEsseboom C, Helders PJ, de Vries LS, et al. Prediction of gross motor development and independent walking in infants born very preterm using the Test of Infant Motor Performance and the Alberta Infant Motor Scale. Early Hum Dev
2013;89(9):693-7. doi: 10.1016/j.earlhumdev.2013.04.016

15. Eickmann SH, Malkes NFA, Lima MC. Psychomotor development of preterm infants aged 6 to 12 months. Sao Paulo Med J 2012;130(5):299-306. doi: 10.1590/s151631802012000500006

16. Ribeiro CD, Pachelli MR, Amaral NC, Lamônica DA. Development skills of children born premature with low and very low birth weight. Codas 2017;29(1):e20160058. doi: $10.1590 / 2317-1782 / 20162016058$

17. Formiga CKMR, Linhares MBM. Motor development curve from 0 to 12 months in infants born preterm. Acta Paediatr 2011;100(3):379-84. doi: 10.1111/j.1651-2227.2010.02002.x.

18. Silveira KA, Enumo SRF. Riscos biopsicossociais para o desenvolvimento de crianças prematuras e com baixo peso. Paidéia 2012;22(53):335-45. doi: 10.1590/S0103863X2012000300005

19. Guerra CC, Barros MC, Goulart AL, Fernandes LV, Kopelman BI, Santos AM. Premature infants with birth weights of 1500-1999 $\mathrm{g}$ exhibit considerable delays in several developmental areas. Acta Paediatr 2014;103(1):e1-6. doi: 10.1111/apa. 12430

20. Giachetta L, Nicolau CM, Costa APBM, Zuana AD. Influência do tempo de hospitalização sobre o desenvolvimento neuromotor de recém-nascidos pré-termo. Fisioter Pesq;17(1):24-9. doi: 10.1590/S1809-29502010000100005

21. Almeida TGA, Caçola PM, Gabbard C, Correr MT, Vilela GB Jr, Santos DCC. Comparações entre o desempenho motor e oportunidades de estimulação motora no ambiente domiciliar de lactentes residentes nas regiões Sudeste e Norte do Brasil. Fisioter Pesq 2015;22(2):142-7. doi: 10.590/18092950/13306322022015

22. Araujo DM, Ribeiro MF, Espíndula AP. Treino materno para estimulação domiciliar sugere melhora no desenvolvimento motor de prematuros. ConScientiae Saúde 2015;14(3):38593. doi:10.5585/ConsSaude.v14n3.5665

23. Sá FE, Nunes NP, Gondim EJL, Almeida AKF, Alencar AC, Cardoso KVV. Parental intervention improves motor development in infants at risk: case series. Fisioter Pesq 2017;24(1):15-21. doi: 10.1590/1809-2950/15828624012017 